\title{
Adsorptive Removal of Formaldehyde by Chemically Bamboo Activated Carbon with addition of Ag nanoparticle: Equilibrium and Kinetic
}

\author{
Wara Dyah Pita Rengga ${ }^{1,2}$, Mahmud Sudibandriyo ${ }^{1}$ and Mohammad Nasikin ${ }^{1}$ \\ ${ }^{1}$ Department of Chemical Engineering, Universitas Indonesia, Kampus UI Depok, Depok 16424, Indonesia \\ 2 Department of Chemical Engineering, Universitas Negeri Semarang, Sekaran Gunungpati Semarang 50229, Indonesia
}

\begin{abstract}
Carbon was prepared from dried waste bamboo (Dendrocalamus asper) using chemical activation with $\mathrm{KOH}$. The carbon was prepared with the activating agent in a mass ratio of $\mathrm{KOH}$ and dried bamboo $(3: 1)$ at $800 \mathrm{oC}$. Using impregnation technique, the bamboo-based activated carbon has developed with modified Ag nanoparticle (Ag-AC) to capture formaldehyde. The Ag-AC has characteristics of moderate surface area of $685 \mathrm{~m} 2 / \mathrm{g}$ and average pore size of $2.7 \mathrm{~nm}$. The adsorption equilibriums and kinetics of formaldehyde on Ag-AC measured. The influences of initial formaldehyde on adsorption performance have measured in a batch system. The equilibrium data were evaluated by isotherm models of Langmuir, Freundlich, and Temkin. The Langmuir model well describes the adsorptive removal of formaldehyde on $\mathrm{Ag}-\mathrm{AC}$ in this study. Pseudo-first-order and pseudo-second-order kinetic equations were applied to test the experimental data. The pseudo-second-order exhibited the best fit for kinetic study.
\end{abstract}

\section{Introduction}

The quality of indoor air has become areas of concern since it related to human health, directly. Maintaining adequate indoor air quality through controlling ambient concentrations of formaldehyde is recommended, although the relationships between air quality and formaldehyde rarely determined. Formaldehyde with a high level can cause symptoms such as eye, nose, and throat irritation, chest pains, bronchitis, and prolonged formaldehyde has associated with reduced pulmonary function and asthma [1,2]. General methods are being used to purify the polluted air, including adsorption [3], membrane, absorption, plasma decomposition [4], and photocatalytic oxidation [5] techniques. Considering adsorption has a promising method for controlling low concentration of formaldehyde because of its simple technique and low energy requirement. Activated Carbon (AC) of bamboo (Dendrocalamus asper) is extremely porous material with a moderate surface area and the most widely used as adsorbent. The AC is used for capturing indoor air pollutants at ambient temperature is considered economically feasible. However, AC is a nonpolar adsorbent that sometimes exhibits low selectivity with polar contaminants. In recent years, modified AC with metal nanoparticle was considered a potential adsorption and oxidation catalytic process due to increased capacity to formaldehyde. Chemically bamboo $\mathrm{AC}$ was produced by with the activating agent in a mass ratio of $\mathrm{KOH}$ and dried bamboo $(3: 1)$ at $800^{\circ} \mathrm{C}$. Silver nanoparticles are impregnated on $\mathrm{AC}$ to enhance the adsorption capacity of removal formaldehyde. An interesting fact was that the $\mathrm{Ag}$ nanoparticles dispersed on commercial coal-based AC to effectively remove formaldehyde from air [6]. Silver also possesses high applicability for use in controlling indoor air due to its non-toxic feature [7].

In this study, AC was modified with silver nanoparticles (Ag-AC) to improve their adsorption capacities. It is important to determine the $\mathrm{Ag}-\mathrm{AC}$ by submitting it for the adsorption of formaldehyde and evaluating the equilibrium isotherms and kinetics adsorption of formaldehyde.

\section{Materials and Methods}

\subsection{Materials}

The AC had conducted as Rengga's method [7]. The Bamboo Chars and $\mathrm{KOH}$ were mixed with 1:3 of weight ratio. The immersed bamboo chars in $\mathrm{KOH}$ solution was dehydrated until it formed the slurry. Subsequently, the slurry was activated in a tube-electronic heater at heating rate of $10^{\circ} \mathrm{C} / \mathrm{min}$ in the presence of nitrogen gas with flowing rate of $200 \mathrm{~mL} / \mathrm{min}$. The activation process was continued up to temperature of $800^{\circ} \mathrm{C}$ and maintained for $1 \mathrm{~h}$. The activated product was washed with $\mathrm{HCl}$ followed by rinsing with distilled water until the $\mathrm{pH}$ of the washing effluent was 6 . The activated carbon was dried at $105{ }^{\circ} \mathrm{C}$ and grinded into 200 mesh prior to characterization and adsorption study. 


\subsection{Synthesis Adsorbent}

Silver nanoparticle synthesized was conducted with reduction process similar to Gaedhi's method [8] in the previous paper [7]. As much $4 \mathrm{~mL}$ of $0.1 \mathrm{M} \mathrm{AgNO}_{3}$ added to $1 \mathrm{~L}$ of an aqueous solution with $0.15 \mathrm{wt} \%$ of the soluble starch. The mixture vigorously stirred for $1 \mathrm{~h}$ under atmosphere. The $\mathrm{pH}$ of resulting solution adjusted to 8.0 by adding $\mathrm{NaOH}$ solution. The mixture was maintained at $50{ }^{\circ} \mathrm{C}$ until a change of the reaction solution became yellow. The next step, silver nanoparticles in solution was mixed with $107.9 \mathrm{~g}$ of activated carbon under magnetic stirring, resulting in the deposition of about $4 \mathrm{wt} \%$ of silver nanoparticles on AC. The AC-Ag was filtered then washed with distilled water and dried at $105^{\circ} \mathrm{C}$ until its constant weight.

\subsection{Batch equilibrium studies}

The adsorption tests were performed to determine the addition amounts of $\mathrm{Ag}$ - AC (0.5 g) to capacity adsorption of formaldehyde at various gas-phase concentrations. The test was done into $10 \mathrm{~mL}$ glass vial equipped with a septum, and subsequently the vials was shaken at $25^{\circ} \mathrm{C}$ for $24 \mathrm{~h}$. The inlet and outlet concentrations of formaldehyde in the batch tests were collected using a 0.5 $\mathrm{mL}$ gas-tight syringe. Furthermore, the sample was analyzed immediately by using gas chromatography equipped with a flame ionization detector (GC/FID, Shimadzu GC-2014). In the experiments, procedures of kinetic tests were identical to equilibrium tests of adsorption. The samples were drawn at suitable time intervals. Each experiment continued until equilibrium conditions were reached when no further decrease in the formaldehyde concentration was measured. Initially on the Ag-AC did not contain any formaldehyde. Furthermore, formaldehyde adsorbed was calculated by using Eq. 1.

$$
\mathrm{q}_{\mathrm{e}}=\frac{\mathrm{v}\left(\mathrm{c}_{0}-\mathrm{c}_{\mathrm{t}}\right)}{\mathrm{m}}
$$

where qe is formaldehyde adsorbed at equilibrium $[\mathrm{mg} / \mathrm{g}]$; $\mathrm{V}$ is a volume of adsorbate [L]; $\mathrm{m}$ is the mass of modified adsorbent [g]. The value of $\mathrm{c}_{0}$ is formaldehyde concentration initially, and $c_{t}$ is formaldehyde concentration after adsorption at equilibrium time [ppm], respectively. The best-fit model determined for a system of formaldehyde adsorption, experimental data substituted for equilibrium isotherm model equations and kinetic models. Parameter values of equations were obtained using non-linear regression analysis. The correlation coefficient $\left(\mathrm{R}^{2}\right)$ of the fit these values, were also reported for each model.

\section{Results and Discussion}

The characteristics of pore are shown in Table 1. We calculated the mesoporosity of $\mathrm{AC}$ by $\mathrm{BET}$ and $\mathrm{BJH}$ methods with surface area and average size of pore of $685 \mathrm{~m}^{2} / \mathrm{g}$ and $2.7 \mathrm{~nm}$, respectively.

Tabel 1. The Characteristics of Pores

\begin{tabular}{ccccc}
\hline $\begin{array}{c}\mathrm{S}_{\mathrm{BET}} \\
{\left[\mathrm{m}^{2} / \mathrm{g}\right]}\end{array}$ & $\begin{array}{c}\mathrm{D}_{\mathrm{BET}} \\
{[\mathrm{nm}]}\end{array}$ & $\begin{array}{c}\mathrm{V}_{\text {meso BJH }} \\
{\left[\mathrm{cm}^{3} / \mathrm{g}\right]}\end{array}$ & $\begin{array}{l}\mathrm{V}_{\text {micro BJH }} \\
{\left[\mathrm{cm}^{3} / \mathrm{g}\right]}\end{array}$ & $\begin{array}{c}\mathrm{V}_{\text {BJH }} \\
{\left[\mathrm{cm}^{3} / \mathrm{g}\right]}\end{array}$ \\
\hline 685 & 2.7 & 0.2009 & 0.0336 & 0.2355 \\
\hline
\end{tabular}

\subsection{Isotherm Equilibrium}

In isotherm equilibrium, formaldehyde removal increases with an increase in the initial formaldehyde concentration. Formaldehyde at equilibrium concentration was indicated the maximum of adsorption capacity is shown in Fig. 1. The adsorption process reaches an equilibrium state, occurs when the molecules distribute between gas and solid phase. The data of formaldehyde adsorption equilibrium were analyzed using Langmuir, Freundlich, and Temkin isotherms, based on the equilibrium of the sorption between the adsorbate and adsorbent. The Langmuir model describes a monolayer sorption with a homogenous distribution both energies and sites of sorption The Freundlich model describes the adsorption distribution energy for heterogeneous sites. The Temkin isotherm assumption is the adsorption heat of all the molecules in AC decreases linearly with coverage. In order, removal formaldehyde from indoor for optimization adsorption system is important to be done to establish the most appropriate correlation in equilibrium curve in Fig 1.

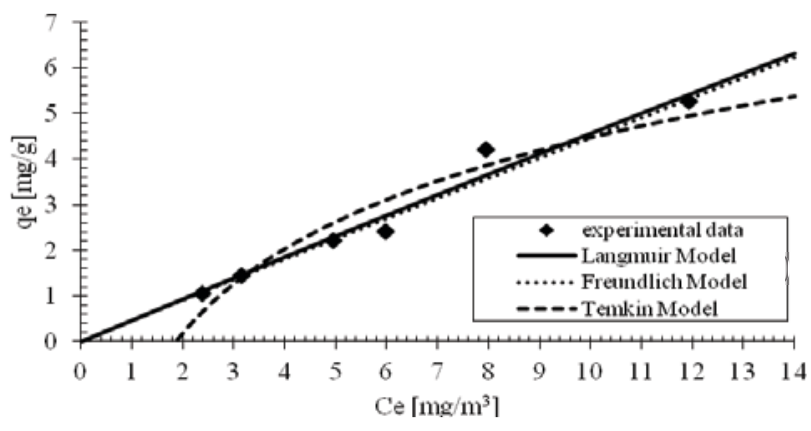

Figure 1. Representation of formaldehyde adsorption on g-AC for Langmuir, Freundlich, and Temkin Models

The Langmuir, Freundlich, and Temkin isotherm equations with their equation are presented in Table 2 . In the Langmuir model, $\mathrm{Q}_{\mathrm{m}}$ is the maximum monolayer coverage adsorption capacity $[\mathrm{mg} / \mathrm{g}]$, and $\mathrm{K}_{\mathrm{L}}$ is the Langmuir isotherm constant $\left[\mathrm{m}^{3} / \mathrm{g}\right]$. In the Freundlich model, the values of $\mathrm{K}_{\mathrm{F}}$ and $\mathrm{n}$ are Freundlich isotherm constant and adsorption intensity. The value of $1 / n$ is the heterogeneity of the adsorbent. The value of $1 / n$ is higher than 1 for favorable adsorption process. In Temkin model, $\mathrm{B}=\mathrm{RT} / \mathrm{b}, \mathrm{R}$ is the universal gas constant $[8.314$ $\mathrm{J} / \mathrm{K} \mathrm{mol}]$, and $\mathrm{T}$ is the absolute temperature $[\mathrm{K}]$. The 
value of $B_{T}$ is constant related to the heat of adsorption $\left[\mathrm{m}^{3} / \mathrm{g}\right]$, and $A_{T}$ is the equilibrium binding constant.

The isotherm constants of adsorption models and correlation coefficients are reported in Table 2. The adsorption of formaldehyde on $\mathrm{Ag}-\mathrm{AC}$ for Langmuir isotherm is shown range studies with high correlation coefficient $\left(\mathrm{R}^{2}>0.96\right)$. Therefore, the conclusion of isotherm that Langmuir model is the best isotherm to predict the adsorption of formaldehyde on Ag-AC adsorbent. It reported that $\mathrm{Ag}-\mathrm{AC}$ had a relatively suitable adsorption capacity of $157.223 \mathrm{mg} / \mathrm{g}$ in this work. The Langmuir model predictions for concentration formaldehyde of $50 \mathrm{mg} / \mathrm{m}^{3}$ using commercial coal-based carbon is $15.8 \mathrm{mg} / \mathrm{g}$ [5] that was close to this study (21 $\mathrm{mg} / \mathrm{g}$ ). Confirmation of the experimental data to the Langmuir isotherm equation proves that the surface of the $\mathrm{Ag}-\mathrm{AC}$ for the adsorption of formaldehyde consists of homogeneous sites. The results are in agreement with previous researchers to the adsorption of pollutants using AC prepared from bone char [9].

Table 2. Parameter of Isotherm Constant and Correlation Coefficient for Adsorption of Formaldehyde on Ag-AC

\begin{tabular}{|c|c|c|c|}
\hline Model & $\begin{array}{l}\text { Non-linear } \\
\text { equation }\end{array}$ & Parameter & Value \\
\hline \multirow[t]{2}{*}{$\begin{array}{l}\text { Langmui } \\
\mathrm{r}\end{array}$} & \multirow[t]{3}{*}{$\mathrm{q}_{\mathrm{e}}=\frac{\mathrm{Q}_{\mathrm{m}} \cdot \mathrm{K}_{\mathrm{L}} \cdot \mathrm{C}_{\mathrm{e}}}{1+\mathrm{K}_{\mathrm{L}} \cdot \mathrm{C}_{\mathrm{e}}}$} & $\begin{array}{l}\mathrm{Q}_{\mathrm{m}}[\mathrm{mg} / \mathrm{g}] \\
\mathrm{K}_{\mathrm{L}}\left(\left[\mathrm{m}^{3} / \mathrm{mg}\right]\right.\end{array}$ & $\begin{array}{c}157.2 \\
23 \\
0.003 \\
0\end{array}$ \\
\hline & & $\mathrm{R}^{2}$ & 0.966 \\
\hline \multirow{3}{*}{$\begin{array}{c}\text { Freundli } \\
\text { ch }\end{array}$} & & $1 / \mathrm{n}$ & 1.005 \\
\hline & \multirow[t]{2}{*}{$\mathrm{q}_{\mathrm{e}}=\mathrm{K}_{\mathrm{F}} \cdot \mathrm{C}_{\mathrm{e}}{ }^{1 / \mathrm{n}}$} & $\underset{[\mathrm{mg} / \mathrm{g}]\left[\mathrm{m}^{3} / \mathrm{m}\right.}{\mathrm{g}]^{1 / \mathrm{n}}}$ & 0.466 \\
\hline & & $\mathrm{R}^{2}$ & 0.962 \\
\hline \multirow{3}{*}{ Temkin } & \multirow{3}{*}{$\mathrm{q}_{\mathrm{e}}\left(\frac{\mathrm{KI}}{\mathrm{b}_{\mathrm{T}}}\right) \cdot \ln \left(\mathrm{A}_{\mathrm{T}} \mathrm{C}_{\mathrm{t}}\right.$} & $\left(\frac{\mathrm{RT}}{\mathrm{b}_{\mathrm{T}}}\right)[\mathrm{J} / \mathrm{mol}]$ & 2.668 \\
\hline & & $\mathrm{A}_{\mathrm{T}}\left[\mathrm{m}^{3} / \mathrm{mg}\right]$ & 0.536 \\
\hline & & $\mathrm{R}^{2}$ & 0.925 \\
\hline
\end{tabular}

\subsection{Adsorption kinetic}

The kinetics of adsorption of formaldehyde on Ag-AC were investigated by using pseudo-first-order and pseudo-second-order models. The pseudo-first-order and pseudo second-order kinetic models of $\mathrm{k}_{1}, \mathrm{k}_{2}$, and $\mathrm{R}^{2}$ are presented in Table 3 . The value of $\mathrm{k}_{1}$ is the adsorption rate constant $(1 / \mathrm{h})$ dan $\mathrm{k}_{2}$ is the rate constant of secondorder adsorption (g/mg.h). The values of $\mathrm{q}_{\mathrm{e}}$ and $\mathrm{q}_{\mathrm{t}}$ are the amounts of formaldehyde adsorbed at equilibrium and time $\left[\mathrm{mg} / \mathrm{g}\right.$ ], respectively. It can see that the values of $\mathrm{R}^{2}$ obtained did not trend consistently at low formaldehyde initial concentration for the pseudo-first-order model. The pseudo-second-order model predicts the behavior of the concentration range adsorption. Between the experimental and the calculated $\mathrm{q}_{\mathrm{e}}$ values (Fig. 2) have a good agreement. Besides that the experimental $\mathrm{q}_{\mathrm{e}}$ value agree with the estimated $\mathrm{q}_{\mathrm{e}}$ values obtained from nonlinear. Obtained that the correlation coefficient values $\mathrm{R}^{2}$ $=0.995$ for the second-order kinetic model, it is clear that the adsorption follows this model. The value of $\mathrm{R}^{2}$ was close to unity, indicating that Ag-AC fitted well to this model for the adsorption of formaldehyde. Between these models, the criterion for their applicability is based on judgment on the respective $\mathrm{R}^{2}$ with the high values indicates that the understudy kinetic of formaldehyde adsorption follows pseudo-second-order model. Agreed the results of the work performed by previous researchers for adsorption of formaldehyde pollutants using activated carbon prepared from bone char [9]. Wu et al. [10] reported that the pseudo second-order model were suitable for adsorption of adsorbate with low molecular weight on smaller adsorbent particles as described for this work.

Tabel 3. Kinetic Parameter for The Adsorption of Formaldehyde on Ag-AC

\begin{tabular}{|c|c|c|c|}
\hline Kinetic Model & $\begin{array}{l}\text { Non-linear } \\
\text { equation }\end{array}$ & Parameter & Value \\
\hline $\begin{array}{l}\text { Pseudo-first- } \\
\text { order }\end{array}$ & $\begin{array}{l}\mathrm{q}_{\mathrm{t}}=\mathrm{q}_{\mathrm{e}}[1- \\
\left.\exp \left(-\mathrm{k}_{1} \cdot \mathrm{t}\right)\right]\end{array}$ & $\mathrm{R}^{2^{\mathrm{k}_{1}[1 / \mathrm{h}]}}$ & $\begin{array}{l}0.333 \\
0.991\end{array}$ \\
\hline $\begin{array}{l}\text { pseudo-second } \\
\text { order }\end{array}$ & $\begin{array}{l}\mathrm{q}_{\mathrm{t}} \\
=\cdot \mathrm{q}_{\mathrm{e}}^{2} \mathrm{k}_{2} \cdot \mathrm{t} /(1 \\
\left.+\mathrm{q}_{\mathrm{e}} \mathrm{k}_{2} \cdot \mathrm{t}\right)\end{array}$ & $\begin{array}{l}\mathrm{k}_{2}[\mathrm{~g} / \mathrm{mg} \cdot \mathrm{h}] \\
\mathrm{R}^{2}\end{array}$ & $\begin{array}{c}0.00015 \\
0.995\end{array}$ \\
\hline
\end{tabular}

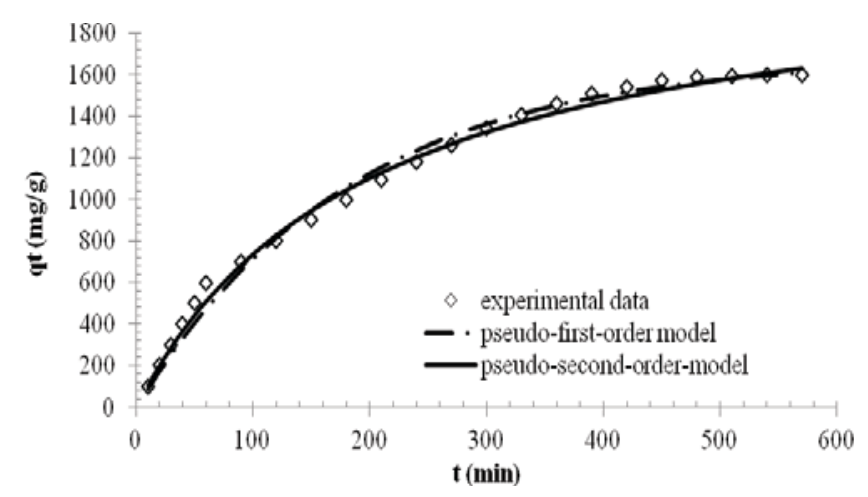

Figure 2. Pseudo-first-order and pseudo-second-order kinetics plot for the adsorption of formaldehyde on $\mathrm{Ag}-\mathrm{AC}$

\section{Conclusions}

The present investigation showed that low concentration formaldehyde by chemically activated carbon of bamboo modified with Ag nanoparticles is an effective adsorption. In the equilibrium condition, adsorption using modified activated carbon is appropriater with Langmuir isotherm model, as well as Freundlich and Temkin models. Isothermal equilibrium model is suitable Langmuir monolayer adsorption model, with adsorption capacity of $157.223 \mathrm{mg} / \mathrm{g}$. For kinetics adsorption of formaldehyde using modified activated carbon, the uses of pseudosecond-order model is more appropriate rather than pseudo-first-order-model. 


\section{Acknowledgements}

We gratefully acknowledge Directorate General of Higher Education, Indonesian Ministry of National Education, Universitas Negeri Semarang, and Universitas Indonesia to support and assist of this work. (Fundamental Research Grant No. 523/UN37.3.1/LT/2015).

\section{References}

1. C.M. Thompson, R.P. Subramaniam and R.C. Grafstrom: Toxicol. Appl. Pharmacol Vol. 233 (2008), p. 355

2. P. Chin, L.P. Yang and D.F. Ollis: J. Catal. Vol. 237 (2006), p. 29

3. S. Kumagai, K. Sasaki, Y. Shimizu and K. Takeda: Sep. Purif. Technol. Vol. 61 (2008), p. 398
4. L. Fang, G. Zhang and A. Wisthaler: Indoor Air Vol. 18 (2008), p. 375

5. N. An, Q. Yu, G. Liu, S. Li, M. Jia and W. Zhang: J. Hazard. Mater. Vol. 186 (2011), p. 1392

6. S. K. Shin and J. H. Song: J. Hazard. Mater. Vol. 194 (2011), p. 385

7. W.D.P. Rengga, M. Sudibandriyo and M. Nasikin: IJCEA Vol. 4,(2013), p. 334.

8. M. Ghaedi, M.N. Biyareh, S.N. Kokhdan, S. Shamsaldini, R. Sahraei, A. Daneshfar and S. Shahriyar: Mater. Sci. Eng Vol. C32 (2012), p. 725

9. A. Rezaee, H-A Rangkooy, A. Khavanin, A. JonidiJafari, R.D.C. Soltani and A. Nili-Ahmadabadi: IJCEA Vol. 2 (2011), p. 423.

10. F.C. Wu, R.L. Tseng, S.C. Huang and R.S. Juang: Chem. Eng. J. Vol. 151 (2009), p. 1. 